\title{
openheart Advanced therapies for the management of adults with pulmonary arterial hypertension due to congenital heart disease: a systematic review
}

\author{
Daniel L Varela, ${ }^{1,2}$ Mohamed Teleb, ${ }^{2,3,4}$ Wael El-Mallah, ${ }^{2,3,4,5}$
}

To cite: Varela DL, Teleb M, El-Mallah W. Advanced therapies for the management of adults with pulmonary arterial hypertension due to congenital heart disease: a systematic review. Open Heart 2018;5:e000744. doi:10.1136/ openhrt-2017-000744

Received 3 November 2017 Revised 21 November 2017 Accepted 22 November 2017

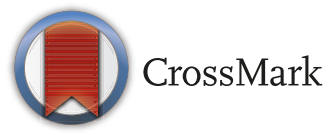

1 Division of Internal Medicine, University of Colorado School of Medicine, Aurora, Colorado, USA ${ }^{2}$ Texas Tech University Health Sciences Center- El Paso Paul L. Foster School of Medicine, El Paso, Texas, USA

${ }^{3}$ Department of Internal Medicine, University Medical Center, El Paso, Texas, USA ${ }^{4}$ Department of Cardiology, University Medical Center, El Paso, Texas, USA

${ }^{5}$ Department of Cardiology, University of Connecticut Health Center, Farmington, Connecticut, USA

\section{Correspondence to}

Dr Daniel L Varela, Division of Internal Medicine, University of Colorado School of Medicine, Aurora, Colorado, USA; daniel. varela@ucdenver.edu

\section{ABSTRACT}

Pulmonary arterial hypertension $(\mathrm{PAH})$ secondary to congenital heart disease (CHD) is the third most common cause of $\mathrm{PAH}$, and it is becoming increasingly common as improvements in the management of $\mathrm{CHD}$ have led to increased life expectancy for these patients. The medical management of PAH due to $\mathrm{CHD}$ (PAH-CHD) is largely the same as what has been used for the treatment of idiopathic PAH, though the body of literature supporting this management decision is very small. There are currently few studies available which specifically focus on the treatment of PAH-CHD. The purpose of this literature review is to compare the results of those studies that assessed the response to medical therapy among adults with PAH-CHD; studies were excluded if they focused on paediatric patients, did not include an assessment of $6 \mathrm{~min}$ walking distance or specifically assessed combination therapies. This review found that riociguat, bosentan, epoprostenol and sildenafil were all capable of improving functional capacity and haemodynamic parameters in patients with $\mathrm{PAH}-\mathrm{CHD}$, but whether this corresponds to an increase in mortality remains to be seen. Limitations of this review include the small sample size and variable duration of the included studies, which makes drawing direct comparisons between studies and the study drugs difficult. The lack of large, randomised double-blind clinical trials comparing different drugs head to head highlights an area that is ripe for ongoing medical research, the results of which may help shape future treatment algorithms tailored specifically for adults with PAH-CHD.

\section{INTRODUCTION}

Pulmonary arterial hypertension $(\mathrm{PAH})$ is a haemodynamic disorder defined as a mean pulmonary arterial pressure $(\mathrm{mPAP})>25 \mathrm{~mm}$ $\mathrm{Hg}$ at rest during right heart catheterisation (RHC). This increase in mPAP causes increased pulmonary vascular resistance (PVR) and cardiac remodelling, which eventually gives rise to right heart failure. ${ }^{1} \mathrm{PAH}$ is most often idiopathic (IPAH) but it can also arise from a number of underlying medical conditions, including connective tissue disease, chronic thromboembolic pulmonary disease and congenital heart disease, among others $^{2}$ (box). PAH due to congenital heart disease (PAH-CHD) refers to PAH that is associated with small cardiac defects (ventricular septal defects (VSDs) $<1 \mathrm{~cm}$ or atrial septal defects (ASDs) $<2 \mathrm{~cm}$ ), systemic-to-pulmonary shunts, Eisenmenger syndrome (ES) or corrective cardiac surgery $^{2}$ (table 1 ). While each cardiac defect is included in a single encompassing group, the aforementioned causes of PAH-CHD differ significantly in terms of pathophysiology, illness severity and risk of developing PAH-CHD (table 2). PAH-CHD is the second most common cause of PAH due to an underlying medical condition (second to PAH due to connective tissue disease). Congenital heart disease is a common disorder, affecting $1 \%$ of newborns; the development of PAH-CHD among patients with septal defects was $6.1 \%$, and the development of PAH-CHD among patients with systemic-to-pulmonary shunts has been estimated to range between $0.00016 \%$ and $0.00125 \% .^{3}$ The most severe cases of PAH-CHD are often those associated with ES and corrective cardiac surgery.

In PAH-CHD, the associated heart defect causes increased pulmonary blood flow which exerts excess stress and pressure on the pulmonary endothelium, and from here, the underlying pathophysiology is considered to be the same as the pathophysiology behind other forms of $\mathrm{PAH}^{3}$ : the pathological stresses on the pulmonary endothelium result in endothelial dysfunction, impaired synthesis of the vasodilatory nitric oxide (NO) and prostacyclin, and overproduction of the vasoconstricting thromboxane A2 and endothelin; the net result is increased pulmonary vascular tone, remodelling of the pulmonary vasculature and impaired pulmonary blood flow. ${ }^{3}$ Because the pathophysiology behind PAH-CHD is so similar to what is seen in the other forms of PAH, the medical management of PAH-CHD is based largely on what has been used to treat the other forms of 
Box Updated clinical classification of pulmonary hypertension (Nice, 2013)

1. Pulmonary arterial hypertension

1.1. Idiopathic $\mathrm{PAH}$

1.2. Heritable PAH

1.2.1. BMPR2

1.2.2. ALK1, ENG, SMAD9, CAV1, KCNK3

1.2.3. Unknown

1.3. Drug-induced and toxin-induced

1.4. Associated with

1.4.1. Connective tissue diseases

1.4.2. HIV infection

1.4.3. Portal hypertension

1.4.4. Congenital heart diseases

1.4.5. Schistosomiasis

$1^{\prime}$. Pulmonary veno-occlusive disease and/or pulmonary capillary

haemangiomatosis

1". Persistent pulmonary hypertension of the newborn

2. Pulmonary hypertension due to left heart disease

2.1. Left ventricular systolic dysfunction

2.2. Left ventricular diastolic dysfunction

2.3. Valvular disease

2.4. Congenital/acquired left heart inflow/outflow tract obstruction and congenital cardiomyopathies

3. Pulmonary hypertension due to lung diseases and/or hypoxia

3.1. Chronic obstructive pulmonary disease

3.2. Interstitial lung disease

3.3. Other pulmonary diseases with mixed restrictive and

obstructive pattern

3.4. Sleep-disordered breathing

3.5. Alveolar hypoventilation disorders

3.6. Chronic exposure to high altitude

3.7. Developmental lung diseases

4. Chronic thromboembolic pulmonary hypertension

5. Pulmonary hypertension with unclear multifactorial mechanisms

5.1. Haematological disorders: chronic haemolytic anaemia,

myeloproliferative disorders, splenectomy

5.2. Systemic disorders: sarcoidosis, pulmonary histiocytosis:

lymphangioleiomyomatosis

5.3. Metabolic disorders: glycogen storage disorders, Gaucher disease, thyroid disorders

5.4. Others: tumorous obstruction, fibrosing mediastinitis, chronic renal failure, segmental $\mathrm{PH}$

ALK1, activin receptor-like kinase 1; BMPR2, bone morphogenetic protein receptor type 2; CAV1, caveolin-1; ENG, endoglin; $\mathrm{PAH}$, pulmonary arterial hypertension. Adapted with permission from Simonneau. ${ }^{2}$

PAH. ${ }^{4}$ However, despite the similar pathophysiology, the catalyst of this process (ie, structural heart disease) is not the same as the underlying mechanism for other types of $\mathrm{PAH}$, and the medical therapies which have been shown to be effective for one type of PAH may not necessarily translate to the same level of efficacy for PAH-CHD or the other types of PAH.

Presently, there are a number of studies which assess the medical management of PAH. Many of these studies focus on treating patients with PAH without differentiating between the aforementioned subtypes; among the studies which do focus on treatment of specific subtypes of PAH, IPAH and PAH due to connective tissue disease have been particularly well studied. Recently, there has been a growing interest in the medical management of PAH-CHD because the number of patients living with $\mathrm{PAH}-\mathrm{CHD}$ is on the rise due to improvements in the surgical treatment of congenital heart disease and subsequent increase in life expectancy. Guidelines specific to the medical management of PAH-CHD are currently lacking, though the same algorithm used for the treatment of IPAH is well-accepted, ${ }^{3}$ with one exception: vasoreactivity testing does not help guide management of patients with PAH-CHD. While there is some evidence to suggest that vasoreactivity testing may have prognostic value for these patients, testing differs for patients with PAH-CHD compared with other forms of PAH in that it does not serve as an indication to begin treatment with a calcium channel blocker as these agents have only been shown to have benefit for patients with IPAH and anorexigen-induced $\mathrm{PAH}^{5}$ and may actually be detrimental to patients with ES (because the systemic vasodilation and the negative inotropic effects of calcium channel blockers may exacerbate the degree of right-to-left shunting). For patients with PAH-CHD, treatment begins with management of their CHD and associated heart failure using conventional therapies: oxygen, anticoagulation, digoxin and cautious use of diuretics. ${ }^{6}$ If the patient remains symptomatic, the next step is to add an endothelin receptor antagonist (ERA) or phosphodiesterase-5 (PDE-5) inhibitor; persistent symptoms are then managed with the addition of a prostanoid; finally, patients who have failed medical management may benefit from balloon atrial septostomy or lung transplant (figure 1).

To date, the prostanoid epoprostenol is the only medication shown to improve mortality in $\mathrm{PAH},{ }^{7}$ though the most well-studied medication for the management of PAH-CHD is the ERA bosentan, which has demonstrated both functional and haemodynamic improvement in patients with PAH-CHD. The effects of bosentan have resulted in improved exercise tolerance and better quality of life in patients with PAH-CHD, while its oral route of administration, favourable side effect profile and more affordable cost have made it the preferred first-line choice for management of PAH-CHD, while epoprostenol is often added on if patients continue to deteriorate while on bosentan. Other prostanoids and ERAs, as well as PDE-5 inhibitors such as sildenafil, have also been used in various combinations for the treatment of PAH-CHD. Recently, a new drug for PAH, the soluble guanylate cyclase (sGC) stimulator, riociguat, has been studied for the treatment of PAH-CHD, with promising results. ${ }^{1}$ The role that each medication plays in reducing or reversing the pathophysiological effects of PAH is illustrated in figure 2.

This review will compare the effects of medical management on several functional parameters affected by PAH-CHD: $6 \mathrm{~min}$ walking distance (6MWD) and WHO functional classification (WHO FC) ${ }^{8}$ (table 3). It will also compare the effects on several haemodynamic 
Table 1 Nice 2013 world symposium on pulmonary hypertension's clinical classification of congenital systemic-to-pulmonary shunts associated with $\mathrm{PAH}$

A. Eisenmenger syndrome Includes all large intracardiac and extracardiac defects which begin as systemic-to-pulmonary shunts and progress with time to severe elevation of PVR and to reversal (pulmonary-to-systemic) or bidirectional shunting; cyanosis, secondary erythrocytosis and multiple-organ involvement are usually present.

B. Left-to-right shunts $\quad$ Correctable

Include moderate-to-large defects; PVR is mildly to moderately increased, systemic-to-pulmonary shunting is still prevalent, whereas cyanosis is not a feature.

\begin{tabular}{ll} 
C. PAH with coincidental CHD & $\begin{array}{l}\text { Marked elevation in PVR in the presence of small cardiac defects, which themselves do not account for the development } \\
\text { of elevated PVR; the clinical picture is very similar to idiopathic PAH. To close the defects is contraindicated. }\end{array}$ \\
D. Postoperative PAH & $\begin{array}{l}\text { CHD is repaired but PAH either persists immediately after surgery or recurs/develops months or years after surgery in } \\
\text { the absence of significant postoperative haemodynamic lesions. The clinical phenotype is often aggressive. }\end{array}$ \\
\hline
\end{tabular}

Adapted with permission from Simonneau. ${ }^{2}$

$\mathrm{CHD}$, congenital heart disease; $\mathrm{PAH}$, pulmonary arterial hypertension; PVR, pulmonary vascular resistance.

parameters: PVR, MPAP and serum levels of the N-terminal of the prohormone of brain natriuretic peptide (NT-proBNP).

Studies were included if they exclusively enrolled patients with PAH-CHD or if they enrolled patients with PAH due to various aetiologies and subgroup analysis was performed to allow for evaluation of the medication's effects specifically on patients with PAH-CHD. Studies were excluded from this review if they did not enrol patients with PAH-CHD or if they enrolled patients with PAH-CHD, but subgroup analysis was not performed, making it difficult to determine whether the results obtained were affected by the inclusion of patients with PAH aetiologies apart from CHD. Studies were also excluded if they did not include an assessment of 6MWD (as this is the primary endpoint in most studies on PAH and is the most widely used test for exercise tolerance and functional capacity among patients with $\mathrm{PAH}$ ) or if they specifically evaluated the effects of combination therapy (ie, more than one drug started simultaneously-though patients were allowed to receive PAH medications other than the study drug so long as they had either been on these other medications prior to the start of the study

Table 2 Prevalence of pulmonary arterial hypertension among various cardiac defects

\begin{tabular}{lc}
\hline Cardiac defect & Prevalence (\%) \\
\hline Closed ASD & 12 \\
Open ASD without ES & 33 \\
Open ASD with ES & 100 \\
Closed VSD & 13 \\
Open VSD without ES & 11 \\
Open VSD with ES & 100 \\
Cyanotic defect (other than ASD or VSD) without ES & 12 \\
Cyanotic defect (other than ASD or VSD) with ES & 100 \\
\hline
\end{tabular}

Original table, based on data presented by Engelfriet, et al. ${ }^{51}$ ASD, atrial septal defect; ES, Eisenmenger syndrome; VSD, ventricular septal defect. or if they required these additional medications due to clinical deterioration while receiving the study drug). Because this review is intended to evaluate medical therapies for adult patients with PAH-CHD, studies focusing on paediatric patients were also excluded. Table 4 provides a summary of the findings from each of the studies discussed in this review.

\section{SOLUBLE GUANYLATE CYCLASE STIMULATOR Riociguat}

Riociguat is a new drug approved both for the treatment of PAH and chronic thromboembolic pulmonary hypertension. Riociguat facilitates the binding of sGC to NO by stabilising the NO-sGC bond, and riociguat also directly stimulates sGC activity, independent of NO; both of these interactions result in increased production of cyclic guanosine monophosphate (cGMP) and subsequent vasodilation of the pulmonary vasculature. ${ }^{9}$ Increased cGMP also inhibits smooth muscle proliferation, leucocyte recruitment, platelet aggregation and vascular remodelling. ${ }^{10}$

Two trials evaluating riociguat for PAH recently underwent subgroup analysis to specifically assess the drug's effect on patients with PAH-CHD. ${ }^{1}$ Post hoc subgroup analysis was performed on 35 patients with PAH-CHD following corrective cardiac surgery who were enrolled in the Pulmonary Arterial hyperTENsion sGC-stimulator Trial-1 (PATENT-1) study, a 12-week-long, randomised, double-blind, placebo-controlled phase III clinical trial. The post hoc analysis showed that patients who received riociguat, either low-dose $(1.5 \mathrm{mg})$ or high-dose $(2.5 \mathrm{mg})$ three times daily, experienced a considerable improvement $(>10 \%)$ in 6MWD and PVR from baseline. mPAP also improved in both treatment groups, and $>20 \%$ of patients in both groups experienced an improvement in WHO FC, while the remainder of patients remained in the same class without deterioration. PATENT-1 was one of the few studies to report NT-proBNP levels; the $1.5 \mathrm{mg}$ group saw a $64.50 \%$ reduction in NT-proBNP, and the $2.5 \mathrm{mg}$ group had a $21.55 \%$ reduction. Dyspepsia, 


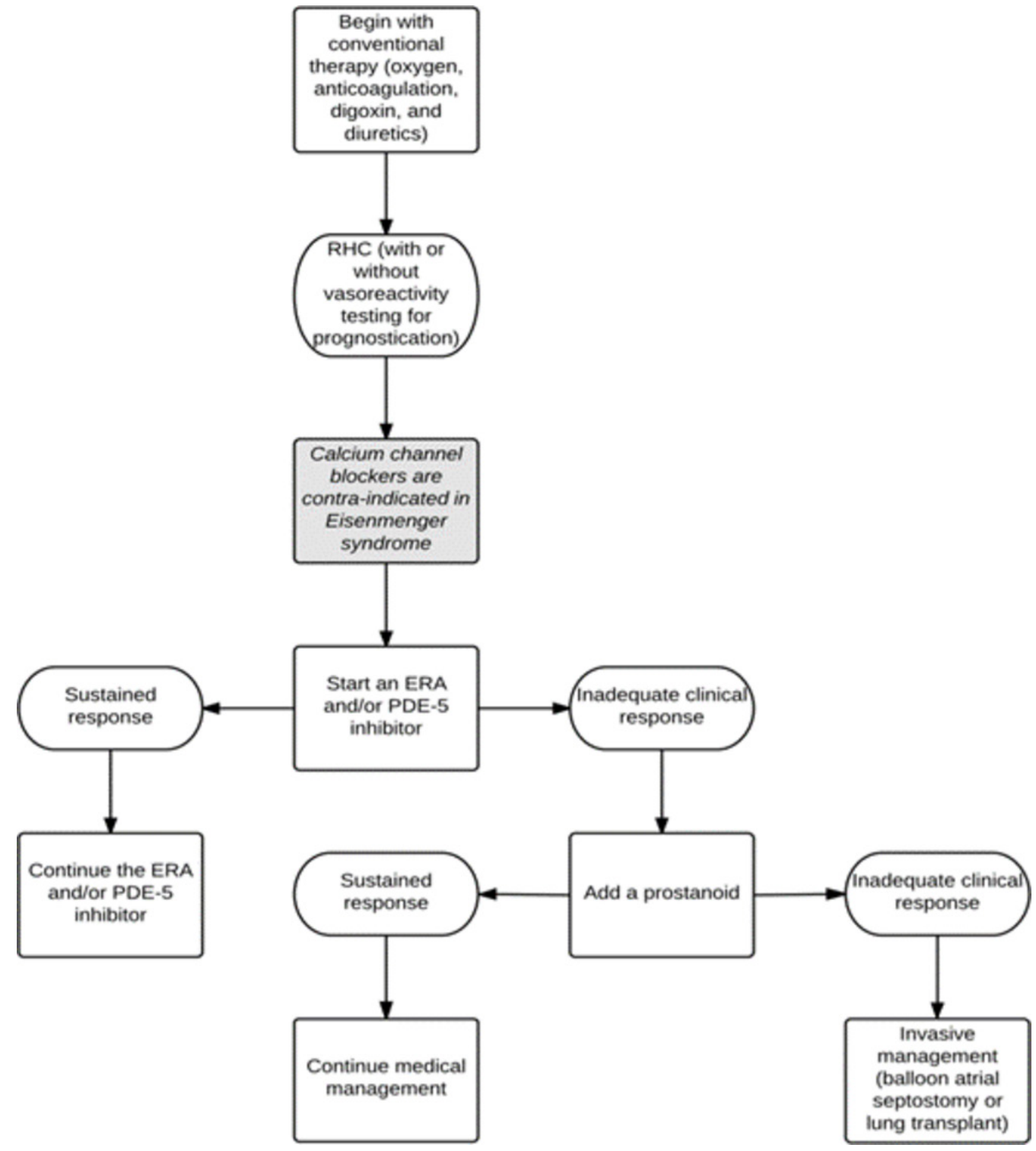

Figure 1 Algorithm for the management of pulmonary arterial hypertension due to congenital heart disease. ERA, endothelin receptor antagonist; PDE-5, phosphodiesterase-5; $\mathrm{RHC}$, right heart catheterisation.

headache and dizziness were the most commonly reported adverse events. One patient in the $2.5 \mathrm{mg}$ group discontinued treatment due to drug-related supraventricular tachycardia and hypotension, and there was one death in the $1.5 \mathrm{mg}$ group due to right ventricular (RV) failure and worsening PAH.

The second post hoc analysis ${ }^{1}$ focused on the Pulmonary Arterial hyperTENsion sGC-stimulator Trial-2 (PATENT-2), a long-term extension of PATENT-1 that followed patients up until 2 years after the start of PATENT-1. PATENT-2 included 33 of the 35 patients with PAH-CHD enrolled in PATENT-1. Patients from the $1.5 \mathrm{mg}$ group, $2.5 \mathrm{mg}$ group and the placebo group received riociguat $2.5 \mathrm{mg}$ three times daily for the duration of the 2-year trial. The former $1.5 \mathrm{mg}$ group experienced only a slight additional improvement in 6MWD, while the former $2.5 \mathrm{mg}$ and placebo groups experienced a marked improvement in 6MWD over the course of
PATENT-2 (an additional 18.70\% improvement was seen in the former $2.5 \mathrm{mg}$ group, while the former placebo group experienced a $9.44 \%$ improvement). Collectively, the population of patients with PAH-CHD who completed PATENT-2 experienced an $18.34 \%$ improvement in $6 \mathrm{MWD} ; 32 \%$ of patients improved to a better WHO FC, $60 \%$ remained stable at the same class and only $8 \%$ deteriorated to a worse class. Regarding adverse effects, 8 of the 33 patients (24\%) were unable to complete the 2-year study due to the development of some form of clinical worsening (defined as hospitalisation due to $\mathrm{PAH}$, requirement for additional PAH medications, decrease in 6MWD or death) during PATENT-2. One of the most serious adverse effects of riociguat is respiratory tract bleeding. There was one episode of this adverse event reported during PATENT-2. Severe hepatic impairment with liver function test (LFT) abnormalities is another serious adverse effect, one which was not observed in any 


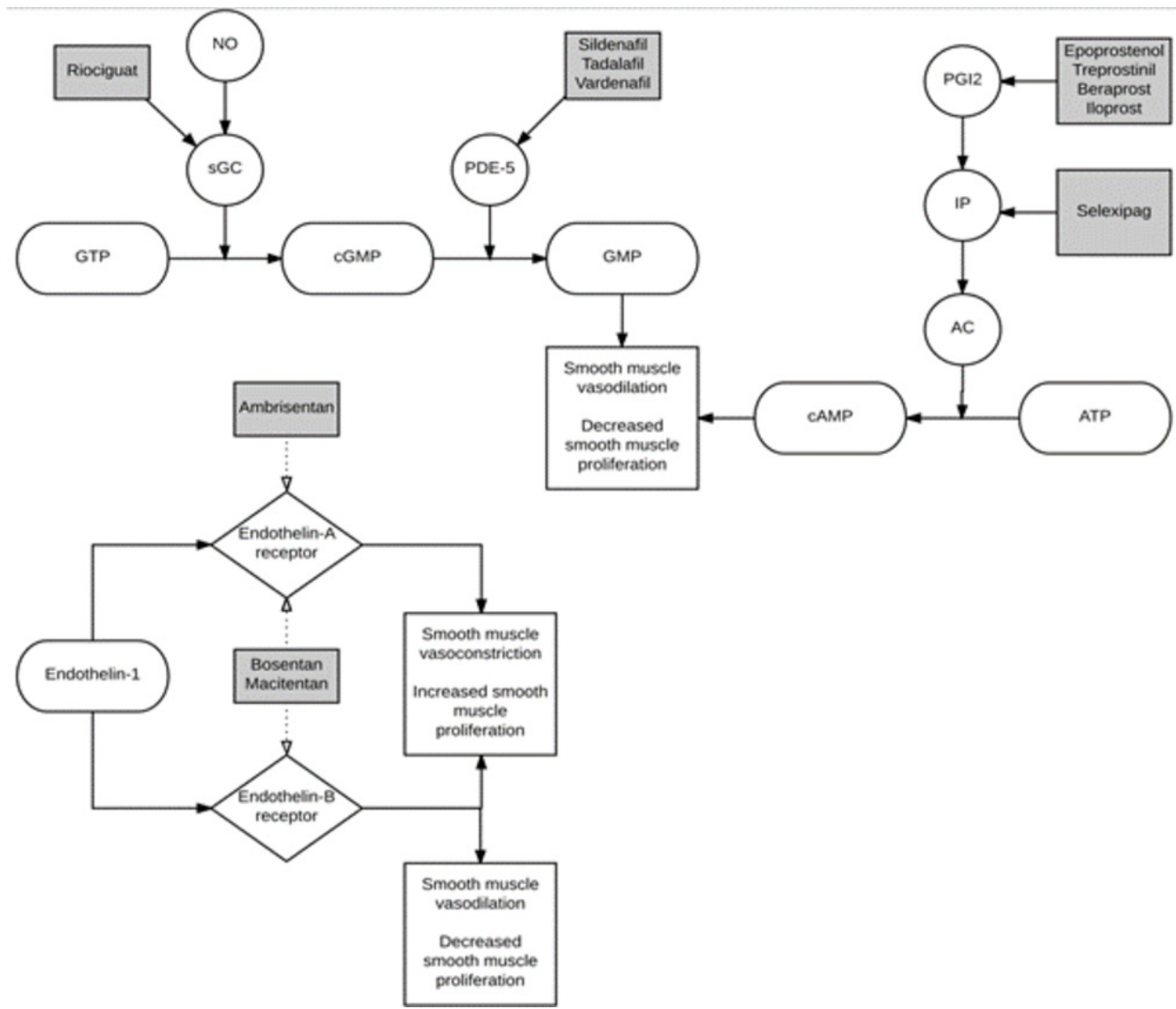

Figure 2 Mechanism of action for pulmonary arterial hypertension medications. Solid black arrows indicate that the compound stimulates its target, facilitates a reaction or induces a change in vascular tone. Dotted white arrows indicate that the compound inhibits its target. AC, adenylyl cyclase; ATP, adenosine triphosphate; cAMP, cyclic adenosine monophosphate; cGMP, cyclic guanosine monophosphate; GMP, guanosine monophosphate; GTP, guanosine triphosphate; IP, prostaglandin I2 receptor; NO, nitric oxide; PDE-5, phosphodiesterase-5; PGI2, prostaglandin I2; sGC, soluble guanylyl cyclase.

patient with PAH-CHD during PATENT-1 or PATENT-2. Additional concerns for riociguat include its contraindication in pregnancy and in patients with systolic blood pressure $<95 \mathrm{~mm} \mathrm{Hg}$ (as well as in patients taking PDE-5 inhibitors, nitrates or NO donors such as amyl nitrate).

\section{ENDOTHELIN RECEPTOR ANTAGONISTS \\ Bosentan}

Endothelin-1 is a vasoconstrictor which is overproduced in the pulmonary vasculature of patients with $\mathrm{PAH}$; overexpression of endothelin results in increased PVR and obstruction of pulmonary blood flow. ERAs, such as bosentan, prevent endothelin-1 from binding to its receptors. ERAs are commonly used to treat patients with PAH. To date, bosentan is the most well-studied drug used in the treatment of PAH-CHD. ${ }^{3}$

Two small, short-term studies supported the use of bosentan in patients with PAH-CHD. Each study observed 10 patients over the course of 3-4 months and found that bosentan improved $6 \mathrm{MWD}$ by $9.21 \%^{11}$

\begin{tabular}{ll}
\hline Table 3 & WHO classification of functional status of patients with pulmonary hypertension \\
\hline Class & Description \\
\hline I & $\begin{array}{l}\text { Patients with pulmonary hypertension in whom there is no limitation of usual physical activity; ordinary physical activity does not } \\
\text { cause increased dyspnoea, fatigue, chest pain or presyncope. }\end{array}$ \\
II & $\begin{array}{l}\text { Patients with pulmonary hypertension who have mild limitation of physical activity. There is no discomfort at rest, but normal physical } \\
\text { activity causes increased dyspnoea, fatigue, chest pain or presyncope. }\end{array}$ \\
III & $\begin{array}{l}\text { Patients with pulmonary hypertension who have a marked limitation of physical activity. There is no discomfort at rest, but less than } \\
\text { ordinary activity causes increased dyspnoea, fatigue, chest pain or presyncope. }\end{array}$ \\
IV & $\begin{array}{l}\text { Patients with pulmonary hypertension who are unable to perform any physical activity at rest and who may have signs of right } \\
\text { ventricular failure. Dyspnoea and/or fatigue may be present at rest and symptoms are increased by almost any physical activity. }\end{array}$ \\
\hline
\end{tabular}

Adapted with permission from Barst, et al. ${ }^{8}$ 
Table 4 Functional and haemodynamic changes in response to pulmonary arterial hypertension medications among adults with congenital heart disease

\begin{tabular}{|c|c|c|c|c|c|c|}
\hline $\begin{array}{l}\text { Study } \\
\text { (reference) } \\
\text { Trial }\end{array}$ & Drug & Mean duration & Sample size ${ }^{\star}$ & $\begin{array}{l}\% \\
\text { improvement } \\
\text { in mean } \\
6 \mathrm{MWD}\end{array}$ & $\begin{array}{l}\% \\
\text { improvement } \\
\text { in mean PVR }\end{array}$ & $\begin{array}{l}\% \\
\text { improvement } \\
\text { in mean } \\
\text { mPAP }\end{array}$ \\
\hline $\begin{array}{l}\text { Rosenkranz et al } \\
\text { PATENT-1 }\end{array}$ & $\begin{array}{l}\text { (a) Riociguat } 1.5 \mathrm{mg} \text { three } \\
\text { times daily } \\
\text { (b) Riociguat } 2.5 \mathrm{mg} \text { three } \\
\text { times daily } \\
\text { (c) Placebo }\end{array}$ & 12 weeks & $\begin{array}{l}\text { (a) } 8 \\
\text { (b) } 15 \\
\text { (c) } 12\end{array}$ & $\begin{array}{l}\text { (a) } 11.00 \\
\text { (b) } 10.57 \\
\text { (c) No significant } \\
\text { improvement }\end{array}$ & $\begin{array}{l}\text { (a) } 12.03 \\
\text { (b) } 22.12 \\
\text { (c) }-5.03\end{array}$ & $\begin{array}{l}\text { (a) } 4.48 \\
\text { (b) } 6.78 \\
\text { (c) No significant } \\
\text { improvement }\end{array}$ \\
\hline $\begin{array}{l}\text { Rosenkranz et al } \\
\text { PATENT-2 (open- } \\
\text { label extension to } \\
\text { PATENT-1) }\end{array}$ & $\begin{array}{l}\text { Riociguat } 2.5 \mathrm{mg} \text { three } \\
\text { times daily }\end{array}$ & $\begin{array}{l}2 \text { years (an } \\
\text { additional } \\
45 \text { months } \\
\text { following the end } \\
\text { of PATENT-1) }\end{array}$ & $\begin{array}{l}\text { (a) } 6 \text { patients who } \\
\text { were originally in the } \\
\text { riociguat } 1.5 \mathrm{mg} \text { arm of } \\
\text { PATENT-1 } \\
\text { (b) } 10 \text { patients who } \\
\text { were originally in the } \\
\text { riociguat } 2.5 \mathrm{mg} \text { arm of } \\
\text { PATENT-1 } \\
\text { (c) } 9 \text { patients who were } \\
\text { originally in the placebo } \\
\text { arm of PATENT-1 } \\
\text { (d) } 25 \text { (total number of } \\
\text { patients who completed } \\
\text { PATENT-2) }\end{array}$ & $\begin{array}{l}\text { (a) } 13.55 \dagger \\
\text { (b) } 29.27 \dagger \\
\text { (c) } 9.44 \dagger \\
\text { (d) } 18.34 \dagger\end{array}$ & Not reported & Not reported \\
\hline Ibrahim et al ${ }^{11}$ & Bosentan & 16 weeks & 10 & 9.21 & Not reported & Not reported \\
\hline Gatzoulis et $a l^{12}$ & Bosentan & 3 months & 10 & 39.76 & Not reported & Not reported \\
\hline D'Alto et al $^{13}$ & Bosentan & 1 year & 24 & 23.13 & 36.36 & Not reported \\
\hline Benza et al ${ }^{14}$ & Bosentan & 1 year & 24 & 10.37 & 23.98 & 13.33 \\
\hline Kotlyar et al ${ }^{15}$ & Bosentan & 15 months & $\begin{array}{l}\text { (a) } 17 \text { treatment-naive } \\
\text { patients } \\
\text { (b) } 6 \text { patients already } \\
\text { receiving PAH-specific } \\
\text { therapy }\end{array}$ & $\begin{array}{l}\text { (a) } 8.49 \\
\text { (b) No significant } \\
\text { improvement }\end{array}$ & Not reported & Not reported \\
\hline Diller et $a l^{18}$ & Bosentan & 2 years & 18 & 43.66 & Not reported & Not reported \\
\hline $\begin{array}{l}\text { Galiè et } a l^{19} \\
\text { BREATHE-5 }\end{array}$ & $\begin{array}{l}\text { (a) Bosentan } \\
\text { (b) Placebo }\end{array}$ & 16 weeks & $\begin{array}{l}\text { (a) } 37 \\
\text { (b) } 17\end{array}$ & $\begin{array}{l}\text { (a) } 12.08 \\
\text { (b) }-2.74\end{array}$ & $\begin{array}{l}\text { (a) } 9.30 \\
\text { (b) }-5.40\end{array}$ & $\begin{array}{l}\text { (a) } 7.07 \\
\text { (b) No significant } \\
\text { improvement }\end{array}$ \\
\hline $\begin{array}{l}\text { Gatzoulis et } a^{20} \\
\text { Open-label extension } \\
\text { to BREATHE-5 (19) }\end{array}$ & Bosentan & $\begin{array}{l}40 \text { weeks (an } \\
\text { additional } \\
24 \text { weeks } \\
\text { following the end } \\
\text { of BREATHE-5) }\end{array}$ & $\begin{array}{l}\text { (a) } 26 \text { patients who } \\
\text { were originally in } \\
\text { the bosentan arm of } \\
\text { BREATHE-5 } \\
\text { (b) } 11 \text { patients who } \\
\text { were originally in } \\
\text { the placebo arm of } \\
\text { BREATHE-5 }\end{array}$ & $\begin{array}{l}\text { (a) } 14.20 \dagger \\
\text { (b) } 8.30 \dagger\end{array}$ & Not reported & Not reported \\
\hline $\begin{array}{l}\text { Apostolopoulou et } \\
\mathrm{al}^{21}\end{array}$ & Bosentan & 16 weeks & 21 & 11.03 & 22.66 & 6.90 \\
\hline
\end{tabular}




\begin{tabular}{|c|c|c|c|c|c|c|}
\hline $\begin{array}{l}\text { Study } \\
\text { (reference) } \\
\text { Trial }\end{array}$ & Drug & Mean duration & Sample size* & $\begin{array}{l}\% \\
\text { improvement } \\
\text { in mean } \\
6 \mathrm{MWD}\end{array}$ & $\begin{array}{l}\% \\
\text { improvement } \\
\text { in mean PVR }\end{array}$ & $\begin{array}{l}\% \\
\text { improvement } \\
\text { in mean } \\
\text { mPAP }\end{array}$ \\
\hline $\begin{array}{l}\text { Apostolopoulou et } \\
\text { al }^{22} \\
\text { Extension to the } \\
16 \text {-week-long study } \\
\text { by Apostolopoulou }{ }^{21}\end{array}$ & Bosentan & $\begin{array}{l}2 \text { years (an } \\
\text { additional } \\
44 \text { months } \\
\text { following the } \\
\text { end of the initial } \\
16 \text {-week-long } \\
\text { study) }\end{array}$ & 19 & $-3.73 \dagger$ & Not reported & Not reported \\
\hline Van Loon et $a l^{23}$ & Bosentan & $\begin{array}{l}\text { (a) } 1 \text { year } \\
\text { (b) } 2.7 \text { years }\end{array}$ & 20 & $\begin{array}{l}\text { (a) } 12.89 \\
\text { (b) } 5.15 \dagger\end{array}$ & Not reported & Not reported \\
\hline Duffels et $a l^{24}$ & Bosentan & $\begin{array}{l}\text { (a) } 6 \text { months } \\
\text { (b) } 22 \text { months }\end{array}$ & 58 & $\begin{array}{l}\text { (a) } 7.96 \\
\text { (b) } 0 \dagger\end{array}$ & Not reported & Not reported \\
\hline Kermeen et $\left.a\right|^{25}$ & Bosentan or sitaxsentan & 1 year & 49 & 36.88 & Not reported & Not reported \\
\hline D'Alto et $a l^{26}$ & Bosentan & 13.6 months & $\begin{array}{l}\text { (a) } 19 \text { patients with } \\
\text { Down syndrome } \\
\text { (b) } 58 \text { patients without } \\
\text { Down syndrome }\end{array}$ & $\begin{array}{l}\text { (a) } 20.50 \\
\text { (b) } 13.41\end{array}$ & $\begin{array}{l}\text { (a) } 25.00 \\
\text { (b) } 23.10\end{array}$ & $\begin{array}{l}\text { (a) } 9.00 \\
\text { (b) } 0\end{array}$ \\
\hline Herbert et $\left.a\right|^{30}$ & Macitentan & $\begin{array}{l}9.6 \text { months (mean } \\
\text { duration) }\end{array}$ & $\begin{array}{l}\text { (a) } 6 \text { patients naive to } \\
\text { bosentan } \\
\text { (b) } 9 \text { patients previously } \\
\text { treated with bosentan }\end{array}$ & $\begin{array}{l}\text { (a) } 58.85 \\
\text { (b) } 7.71\end{array}$ & Not reported & Not reported \\
\hline Blok et $a l^{31}$ & Macitentan & 6 months & 40 & $\begin{array}{l}\text { No significant } \\
\text { improvement }\end{array}$ & Not reported & Not reported \\
\hline Fernandes et $a l^{32}$ & Epoprostenol & 3 months & 8 & 780.00 & 48.78 & Not reported \\
\hline Rosenzweig et a/ ${ }^{33}$ & Epoprostenol & 1 year & 20 & 12.75 & 52.00 & 20.78 \\
\hline $\begin{array}{l}\text { Galie et } a^{36} \\
\text { ALPHABET }\end{array}$ & $\begin{array}{l}\text { (a) Beraprost } \\
\text { (b) Placebo }\end{array}$ & 12 weeks & $\begin{array}{l}\text { (a) } 9 \\
\text { (b) } 15\end{array}$ & $\begin{array}{l}\text { (a) No significant } \\
\text { improvement } \\
\text { (b) No significant } \\
\text { improvement }\end{array}$ & $\begin{array}{l}\text { (a) No significant } \\
\text { improvement } \\
\text { (b) No significant } \\
\text { improvement }\end{array}$ & $\begin{array}{l}\text { (a) No significant } \\
\text { improvement } \\
\text { (b) No significant } \\
\text { improvement }\end{array}$ \\
\hline Chau et $\left.a\right|^{39}$ & Sildenafil & 6 weeks & 7 & $\begin{array}{l}\text { No significant } \\
\text { improvement }\end{array}$ & 43.08 & 25.71 \\
\hline D'Alto et $a l^{40}$ & Sildenafil & 6 months & 32 & 22.87 & $20.84 \%$ & $\begin{array}{l}\text { No significant } \\
\text { improvement }\end{array}$ \\
\hline Zeng et $a l^{41}$ & Sildenafil & 12 weeks & $\begin{array}{l}\text { (a) } 15 \text { patients with ASD } \\
\text { (b) } 24 \text { patients with VSD } \\
\text { (c) } 16 \text { patients with PDA }\end{array}$ & $\begin{array}{l}\text { (a) } 15.65 \\
\text { (b) } 11.32 \\
\text { (c) } 14.58\end{array}$ & $\begin{array}{l}\text { (a) } 30.89 \\
\text { (b) } 24.76 \\
\text { (c) } 31.72\end{array}$ & $\begin{array}{l}\text { (a) No significant } \\
\text { improvement } \\
\text { (b) } 11.28 \\
\text { (c) No significant } \\
\text { improvement }\end{array}$ \\
\hline $\begin{array}{l}\text { Mukhopadhyay et } \\
\text { al }\end{array}$ & Tadalafil & 12 weeks & 16 & 12.50 & 31.23 & 7.65 \\
\hline
\end{tabular}

*Sample size may not reflect the total number of patients enrolled in each study as it only includes the number of adult patients with PAH$\mathrm{CHD}$ (ie, this table excludes enrolled patients with other forms of PAH and it excludes all paediatric patients).

†Values reported reflect changes from baseline values.

6MWD, 6 min walking distance; ALPHABET, Arterial Pulmonary Hypertension and Beraprost European Trial; ASD, atrial septal defect; BREATHE-5, Bosentan Randomised Trial of Endothelin Antagonist THErapy-5; mPAP, mean pulmonary arterial pressure; PAH, pulmonary arterial hypertension; PAH-CHD, pulmonary arterial hypertension due to congenital heart disease; PATENT-1, Pulmonary Arterial hyperTENsion sGC-stimulator Trial-1; PATENT-2, Pulmonary Arterial hyperTENsion sGC-stimulator Trial-2; PDA patent ductus arteriosus; PVR, pulmonary vascular resistance; VSD, ventricular septal defect; WHO FC, WHO functional class.

and $39.76 \% .^{12}$ One study also reported that WHO FC improved in $50 \%$ of patients and remained stable in the other $50 \% .{ }^{11}$ Two patients experienced serious adverse events requiring hospitalisation in one study (peripheral oedema related to bosentan use and hypoglycaemia unrelated to bosentan use). ${ }^{11}$ The other study reported transient peripheral oedema in four patients, but no serious adverse events. ${ }^{12}$ 
Larger studies on the use of bosentan for up to 1 year of treatment or longer also reported encouraging results, ${ }^{13-18}$ with improvements in $6 \mathrm{MWD}$ ranging between $8.49 \%$ and $43.66 \%$ and improvements in PVR between $23.98 \%$ and $36.36 \%$. One study by Kotlyar $e t a l^{15}$ did note that $6 \mathrm{MWD}$ only improved among their patients who were naive to prior treatment with $\mathrm{PAH}$-specific medications, while those patients who were already receiving some form of therapy did not experience any significant improvement in 6MWD. Most studies also reported a significant improvement in WHO FC in many patients, with only one patient experiencing a worsening of $\mathrm{WHO}$ FC. ${ }^{15}$ Among these studies, four patients discontinued bosentan due to peripheral oedema, ${ }^{13} 1517$ four discontinued due to elevated LFTs, ${ }^{14}{ }^{15}$ two discontinued due to perceived lack of improvement ${ }^{15}$ and two died (one due to worsening PAH, and the other due to progressive heart failure in a patient with 'single ventricle' physiology). ${ }^{15} 18$

The Bosentan Randomised Trial of Endothelin Antagonist THErapy-5 (BREATHE-5) study was the first trial designed as a multicentre, double-blind, randomised, placebo-controlled study that assessed the effects of bosentan on PAH-CHD. ${ }^{19}$ Fifty-four patients with PAH-CHD received either bosentan or placebo for 16 weeks. 6MWD improved by $12.08 \%$ in the bosentan group and decreased by $2.74 \%$ in the placebo group. PVR and mPAP also improved in the bosentan group. Also, 35\% of patients in the bosentan group and $13 \%$ of patients in the placebo group had improved by at least one WHO FC, while one patient in the bosentan group and two patients in the placebo groups deteriorated to a worse class. Peripheral oedema was the most frequent adverse event in the bosentan group, occurring in $19 \%$ of patients. Two patients from each group discontinued treatment (due to angina and elevated LFTs in the treatment group, and due to fatigue and worsening of $\mathrm{PAH}$ in the placebo group). An open-label extension to BREATHE- $5^{20}$ was performed to extend the length of treatment from 16 weeks to 40 weeks in patients who completed the initial study. Patients from both the bosentan and placebo groups received bosentan for 24 weeks following the completion of BREATHE-5. The former bosentan group maintained its improvement in $6 \mathrm{MWD}$, while the former placebo group improved by $8.30 \%$ from baseline. Collectively, the study population experienced a $17.75 \%$ improvement in 6MWD from baseline; $>60 \%$ of all patients improved by at least one WHO FC from baseline. Peripheral oedema, chest pain, nasopharyngitis and diarrhoea were the most frequently reported adverse events. Three patients discontinued treatment (one withdrew consent, another experienced elevated LFTs and the third suffered from considerable abdominal pain, nausea, diarrhoea and lethargy). Another patient experienced a significant drop in haemoglobin during the study.

Unfortunately, not all studies on bosentan have reported such beneficial outcomes following long-term (>1 year) use. Four studies ${ }^{21-24}$ found that the improvements in 6MWD achieved during the first 4-12 months of bosentan therapy began to deteriorate thereafter, dropping back down to baseline, or slightly below baseline. Despite this gradual deterioration in 6MWD, improvements initially seen in WHO FC did persist long term, and no patient experienced deterioration in WHO FC during any of these studies. Despite the improvements in WHO FC, four patients died (three cases of arrhythmia and one case of brain abscess), ${ }^{21}{ }^{24}$ two patients discontinued bosentan (nasopharyngitis and lack of improvement), ${ }^{23}$ one patient experienced an episode of haemoptysis which required hospitalisation, ${ }^{21}$ and four patients required additional PAH medications. ${ }^{23}$ In addition to their adult patients, Van Loon $e t a t^{23}$ also studied a group of paediatric patients. They noticed that among their paediatric patients, who tended to be sicker than the adult patients, the long-term deterioration in 6MWD was more pronounced. Van Loon et al proposed that long-term deterioration in 6MWD may be more likely to occur in patients who suffer from more severe PAH-CHD. Duffels $e t a l^{24}$ performed a subgroup analysis on their patients with PAH-CHD which showed that the beneficial effects of bosentan persisted even after 2 years in the subgroup with ES, but not in the subgroup without ES, suggesting that bosentan's effects are more likely to be maintained long term in patients with ES. Duffels also performed subgroup analysis on patients with Down syndrome and found that 6MWD neither improved nor worsened during treatment (which the authors reported may have been due to the fact that intellectual disability in many patients with Down syndrome may have limited their ability to appropriately complete the 6 min walking test at full effort). However, a separate study on adult patients with Down syndrome by Kermeen $e t a l^{25}$ found a marked improvement in $6 \mathrm{MWD}$ of $36.88 \%$ in response to bosentan (or sitaxsentan for a small number of patients). Kermeen et al attributed this substantial improvement to the possibility that their patients suffered from more advancedPAHandwere thereforemorelikelytoexperience appreciable improvement in exercise capacity following treatment, which goes against the suggestion by Van Loon et al that patients with more severe disease were less likely to respond well to bosentan long term. D'alto $e t a t^{26}$ studied the effects of bosentan on adult patients with and without Down syndrome for 1 year and found that both groups benefited equally in terms of both 6MWD and haemodynamics, though, like Duffels $e t a l$, they noted the questionable validity of the $6 \mathrm{~min}$ walking test for patients with Down syndrome and suggested this as a plausible explanation for the discrepant $6 \mathrm{MWD}$ results reported by Duffels, Kermeen and other studies on patients with Down syndrome. Despite the questionable results of the $6 \mathrm{~min}$ walking test for patients with Down syndrome, D'alto et al did comment that the improved haemodynamics and WHO FC observed were reassuring for the benefits of bosentan among patients with Down syndrome, at least for the first year of treatment. The results of these studies suggest that there is still more to learn about bosentan's long-term efficacy in patients with PAH-CHD 
and whether or not the underlying pathophysiology or severity of disease affects patients' response to treatment.

Peripheral oedema and significant elevations in LFTs were among the most frequently reported adverse effects, the latter being particularly concerning given that hepatotoxicity is one of the most serious potential complications of bosentan therapy. For some patients, reducing the dose of bosentan by half helped resolve the oedema and LFT abnormalities, while for others, the symptoms persisted and they had to discontinue treatment. Anaemia is another concerning adverse reaction to bosentan, though a significant decrease in haemoglobin was only reported in one patient. ${ }^{20}$ Importantly, there was no significant deterioration of arterial oxygen saturation in any study, which is significant because there has been some concern regarding the use of bosentan and other pulmonary vasodilators in patients with PAH-CHD because these agents may cause systemic vasodilation as well, and if the systemic vasodilation occurs to a greater extent than pulmonary vasodilation, then an increase in pulmonary-to-systemic shunting across the structural heart defect may occur, which could cause arterial oxygen saturation to deteriorate, resulting in cyanosis.

\section{Sitaxsentan}

Another ERA, sitaxsentan, has greater selectivity for the endothelin-A receptor (responsible for pulmonary vasoconstriction) over the endothelin-B receptor (responsible for pulmonary vasodilation), while bosentan is rather non-selective. Because endothelin-A is the desired target implicated in the pathophysiology of PAH and because endothelin-B may counteract some of the vasoconstriction mediated by endothelin-A, investigators have suggested that sitaxsentan's selectivity for endothelin-A may make it a preferable drug over bosentan. Sitaxsentan has not been well studied in patients with PAH-CHD. One study by Barst $e t a l^{27}$ showed that patients with PAH, including patients with PAH-CHD, had increased 6MWD, improved WHO FC and decreased PVR following 12 weeks of sitaxsentan therapy. However, subgroup analysis was not performed, making an evaluation of sitaxsentan's effects on patients with PAH-CHD impossible. And in 2010, sitaxsentan was withdrawn from the market and from further clinical trials due to concerns that the risks of hepatotoxicity were greater for this drug than for bosentan and without any evidence of increased efficacy.

\section{Ambrisentan}

Ambrisentan is the third ERA studied for the treatment of PAH. Like sitaxsentan, it is selective for the endothelin-A receptor, but it has not been associated with the same degree of hepatotoxicity, and it may even have a lower risk of hepatotoxicity than bosentan. ${ }^{28}$ The Ambrisentan in Pulmonary Arterial Hypertension, Randomized, Double-Blind, Placebo-Controlled, Multicenter, Efficacy Study 1 (ARIES-1) and the Ambrisentan in Pulmonary Arterial Hypertension, Randomized, DoubleBlind, Placebo-Controlled, Multicenter, Efficacy Study 2
(ARIES-2) trials $^{29}$ have shown improvement in 6MWD in patients with PAH. However, there are currently no studies on the efficacy of ambrisentan in patients with PAH-CHD.

\section{Macitentan}

Macitentan is the newest ERA studied for the treatment of PAH. Like bosentan, macitentan antagonises both the endothelin-A and endothelin-B receptors, though it does exhibit greater selectivity for endothelin-A receptors. Other differences between macitentan and bosentan include macitentan's once-daily dosing (vs twice daily for bosentan), freedom from monthly LFT monitoring and enhanced tissue penetration.

A study by Herbert et $a l^{30}$ was conducted on 15 patients with PAH-CHD of varying aetiologies, the most common of which being a complete or partial atrioventricular septal defect. Eight patients had Down syndrome. Also, 9 of the 15 patients were previously on bosentan and switched to macitentan due to either insufficient response or adverse reaction to bosentan; the remaining 6 patients were ERA naive. After a mean treatment time of approximately 10 months, the study found that as a collective whole the patients exhibited a $25.87 \%$ improvement in 6MWD, with the greatest observed improvement seen among treatment-naive patients $(58.85 \%$ for treatment-naive patients vs $7.71 \%$ for patients previously treated with bosentan). WHO FC remained stable at III for all patients. In this study, one patient discontinued due to rash, while another patient with advanced disease passed away shortly after initiation of therapy. Neither anaemia nor transaminitis were reported as adverse events. A larger study by Blok $e t a l^{31}$ looked to further evaluate the potential benefit of switching from bosentan to macitentan. In total, 40 patients with PAH-CHD, including 16 with Down syndrome, who had already been on bosentan for a median of 7.2 years (some of whom were also on sildenafil) were switched from bosentan to macitentan (patients who were previously on sildenafil were allowed to continue this medication). 6MWD showed no significant improvement. Twenty-five per cent of patients had an improvement in WHO FC. NT-proBNP levels improved by $48.16 \%$. One patient died 4 months after switching to macitentan due to sepsis, but no adverse events were directly attributed to macitentan. While the data supporting macitentan's efficacy in improving $6 \mathrm{MWD}$ are mixed, this may be due to the fact that many of the patients in the above studies had Down syndrome, a group for which the 6 min walking test is not as well validated, as well as the fact that many of the patients in both studies had previously been treated with bosentan, which may have produced more pronounced improvements in 6MWD prior to enrolment, thus blunting potential improvements from macitentan. Despite the mixed data for $6 \mathrm{MWD}$, the improvement and stabilisation in WHO FC, improved NT-proBNP levels, good tolerability and once-daily dosing have provided encouraging results thus far and prompted the authors to advocate for further 
studies to evaluate macitentan's role in the management of PAH-CHD.

\section{PROSTANOIDS \\ Epoprostenol}

Prostacyclin (PGI2) is produced by pulmonary endothelium. It acts as a vasodilator, and it also has anti-inflammatory properties and antiproliferative effects on smooth muscle cells and fibroblasts in the pulmonary vasculature; endothelial damage in PAH results in underproduction of prostacyclin, contributing to the increased pulmonary vascular tone and remodelling. Thus, prostacyclin analogues, such as the intravenous agent epoprostenol, have been used to slow disease progression and improve symptoms for patients with both PAH and PAH-CHD.

In a small study by Fernandes et $a l^{32}$ the effects of epoprostenol were evaluated in eight patients with PAH-CHD. After 3 months of epoprostenol, median 6MWD increased by $780 \%$ (this exceptionally large improvement may be due in part to the small sample size and the fact that the patients started with a significantly diminished mean 6MWD of $44 \mathrm{~m}$ at baseline). All eight patients improved by at least one WHO FC, and PVR decreased by $48.78 \%$. In a larger study by Rosenzweig et $a l^{33} 20$ patients with PAH-CHD who failed conventional therapy (eg, oxygen, anticoagulation, digoxin, and diuretics) were treated with epoprostenol. No patient acutely responded to epoprostenol; however, long-term (1 year) epoprostenol use resulted in a $12.75 \%$ increase in 6MWD, as well as a $52.00 \%$ improvement in PVR, and $20.78 \%$ reduction in mPAP. Seventy per cent of patients improved by at least one WHO FC. In addition to epoprostenol's effects on improving both functional and haemodynamic parameters in patients with PAH-CHD, only epoprostenol has been shown to have a mortality benefit in patients with PAH-CHD. ${ }^{7}$ However, epoprostenol has a very short half-life $(2-7 \mathrm{~min})$; as a result, its only viable route of administration is via continuous intravenous infusion. The necessity of a permanently implanted central venous catheter has resulted in poor patient adherence and the risk of serious complications, including infection or thrombosis of the chronic indwelling central venous catheter, sepsis and delivery system malfunction ${ }^{34}$; other adverse effects include jaw pain, rash, arthralgias, nausea and vomiting. Fernandes et al saw one patient experience an episode of catheter-related sepsis, and in the study by Rosenzweig et al, 14 patients experienced jaw pain, 8 experienced rash, 6 experienced arthralgias, 2 experienced nausea and vomiting, 7 experienced dislodged central venous lines, 4 experienced line infections and 2 experienced pump malfunctions. Due to the significant adverse effects of epoprostenol and the complications associated with its delivery mechanism, current recommendations are to only consider patients for long-term epoprostenol therapy if they fail conventional therapy or if they fail other PAH-specific therapies (eg, bosentan or sildenafil).

\section{Treprostinil}

Treprostinil is another prostanoid approved for the treatment of PAH. It acts similarly to epoprostenol by promoting pulmonary vasodilation and preventing inflammation and smooth muscle proliferation. Treprostinil is most often given in a subcutaneous injection, though intravenous, oral and inhaled forms also exist. Because subcutaneous injection has fewer complications associated with it than intravenous administration, treprostinil has been proposed as an ideal alternative to epoprostenol. Both epoprostenol and treprostinil have been shown to improve survival in patients with $\mathrm{PAH}$, with similar long-term survival reported in patients treated with either agent. ${ }^{34}$ Currently, no studies on the use of treprostinil exclusively in patients with PAH-CHD have been performed.

\section{Beraprost}

Beraprost is another prostanoid used for the treatment of PAH. It is available in pill form and can be taken orally, making it more convenient than both the intravenous epoprostenol and the subcutaneous treprostinil. However, beraprost is less well studied than both of those agents for the treatment of PAH, and further studies are necessary to provide more insight into its role in the treatment of PAH. ${ }^{35}$

Galie et $a \hat{l}^{6}$ looked at the results of the Arterial Pulmonary Hypertension and Beraprost European Trial (ALPHABET), which was a 12-week randomised, doubleblind, placebo-controlled, multicentre study designed to determine the effects of oral administration of beraprost sodium in patients with $\mathrm{PAH}$, including a subset of patients with PAH-CHD. Patients with IPAH had a statistically significant improvement in 6MWD; however, for patients with PAH due to an underlying medical condition such as PAH-CHD, improvements in 6MWD were minimal and not statistically significant. The authors reported that this lack of improvement for patients with PAH due to underlying medical conditions could be explained by a number of reasons. One possible explanation is the small sample size of each subgroup of patients with PAH due to underlying medical conditions. Another explanation is that the doses of beraprost sodium administered to these patients were substantially lower than the doses given to the patients with IPAH $(62 \pm 36 \mu \mathrm{g}$ four times daily vs $96 \pm 35 \mu \mathrm{g}$ four times daily, respectively); dose increase was usually limited by symptoms such as headache, flushing and diarrhoea, which were more common among patients with $\mathrm{PAH}$ due to underlying medical conditions. One last explanation is that a 12 -week study may be too short to demonstrate a beneficial effect of prostanoid therapy in the patients with PAH due to underlying medical conditions, while it may be long enough for a beneficial effect to be seen in patients with IPAH; patients with PAH-CHD due to systemic-to-pulmonary shunt, for example, often have a slower rate of clinical deterioration and a longer preservation of cardiac output, and this may affect the rate at which these patients respond to treatment. 


\section{Iloprost}

An inhaled prostanoid, iloprost, also exists. Iloprost has been shown to have a longer duration of action than epoprostenol (around 30-90 min vs $15 \mathrm{~min}$ ). Iloprost has been shown to result in significant clinical improvement in patients with severe PAH, ${ }^{37}$ though patients with IPAH had greater improvement than patients with $\mathrm{PAH}$ due to underlying medical conditions, and there are currently no studies available that evaluate iloprost's effects specifically in patients with PAH-CHD.

\section{Selexipag}

Selexipag is a new oral medication which acts in a similar fashion to the prostanoids. Specifically, selexipag is a non-prostanoid agent which serves as an agonist at the PGI2 receptor, facilitating the same downstream effects as the prostanoids. The Prostacyclin (PGI2) Receptor Agonist In Pulmonary Arterial Hypertension study showed a reduction in hospitalisation rates and disease progression among patients with $\mathrm{PAH}$ who received selexipag over the course of 3 years, but little effect on mortality. ${ }^{38}$ There was minimal improvement in 6MWD (treatment effect of only $12 \mathrm{~m}$ ), which the authors suggested may have been due to the fact that many patients were already receiving background therapy with either an ERA, PDE-5 inhibitor or both, which may have produced improvements in baseline functional capacity prior to the start of this study, potentially blunting selexipag's treatment effect. The study included 110 patients (10\% of study population) with PAH-CHD due to closed defects, though subgroup analysis was not performed, and data pertaining to selexipag's effects specifically for patients with PAH-CHD due to closed defects are unavailable. There are also no data to support the use of selexipag for patients with PAH-CHD due to other aetiologies apart from closed defects.

\section{PDE-5 INHIBITORS}

\section{Sildenafil}

PDE-5 is an enzyme present in high concentration in the lungs. PDE-5 functions to degrade the cGMP produced after NO binds to sGC; this degradation of cGMP results in impaired pulmonary arterial vasodilation. The role of PDE-5 inhibitors, such as sildenafil, is to block the action of PDE-5, increase cGMP and promote the relaxation of the pulmonary vasculature. The subsequent increase in pulmonary blood flow can help improve the symptoms of patients with PAH.

Chau et $a l^{39}$ conducted a prospective open-label study in which they gave sildenafil to six patients with IPAH and seven patients with PAH-CHD. After 6 months, 6MWD did not show a statistically significant improvement in patients with PAH-CHD, though PVR, mPAP and WHO FC each improved. The authors noted that the adverse effect of significantly decreased systolic blood pressure only occurred in the PAH-CHD group. The authors commented that this may indicate that the systemic vasculature in patients with PAH-CHD may be more sensitive to sildenafil than the systemic vasculature in patients with IPAH. They recommended cautious monitoring for the development of hypotension after starting sildenafil in patients with PAH-CHD.

D'Alto et $a t^{40}$ studied the effects of sildenafil on 32 patients with PAH-CHD and underlying ES who had previously failed to improve with bosentan therapy. After 6 months, they found that the addition of sildenafil resulted in a $22.87 \%$ increase in $6 \mathrm{MWD}$, a $20.84 \%$ reduction in PVR and improved WHO FC from an average of III to II. They also noted a $60.14 \%$ reduction in NT-proBNP level, but no significant change in mPAP. Zeng et at ${ }^{41}$ studied the effects of sildenafil on 55 patients with PAH-CHD over the course of 12 weeks. Patients were separated into three groups according to the location of their congenital heart defect: ASD, VSD and patent ductus arteriosus (PDA). 6MWD increased between $11.32 \%$ and $14.58 \%$ in each group, and PVR decreased between $24.76 \%$ and $31.72 \%$. mPAP decreased only in the VSD group (11.28\%). The authors concluded that sildenafil was able to successfully treat patients with PAH-CHD irrespective of the location of the cardiac defect. The incidence of adverse events was similar among the three groups, occurring in $15 \%$ of patients; headache, flushing, nasal congestion, tinnitus and menorrhagia were the most frequently reported events.

\section{Tadalafil}

Tadalafil is another PDE-5 inhibitor that has been studied for the treatment of PAH. Tadalafil has the same mechanism of action as sildenafil. However, tadalafil's longer half-life (around 18 hours compared with 4 hours) has led some investigators to consider it a suitable alternative to sildenafil. Tadalafil's longer half-life means it can be given once daily, whereas sildenafil is usually given three times daily; as a result, patient adherence may be greater with tadalafil than with sildenafil. Also, in terms of adverse effects, tadalafil is more selective for PDE-5, while sildenafil also inhibits other phosphodiesterases, which may result in increased risk of adverse events such as visual disturbances, flushing and tachycardia. ${ }^{42}$

Mukhopadhyay et $a t^{43}$ studied the effects of tadalafil over a 12-week period in 16 patients with PAH-CHD. 6MWD increased by $12.50 \%$ and PVR decreased by $31.21 \%$; WHO FC improved by at least one class in all 16 patients. No patient experienced any adverse events.

\section{Vardenafil}

Vardenafil is the third major PDE-5 inhibitor. Unlike sildenafil and tadalafil, vardenafil is not currently approved for the treatment of PAH. ${ }^{44}$ Vardenafil was shown to improve 6MWD and CI, while decreasing PVR and mPAP in a 12-week placebo-controlled clinical trial in patients with $\mathrm{PAH}{ }^{45}$ No studies exist to evaluate vardenafil's role in the management of PAH-CHD. 


\section{DISCUSSION}

$\mathrm{PAH}$ is a serious complication of CHD. More than $4 \%$ of patients born with CHD will go on to develop $\mathrm{PAH}$ in adulthood. Without early surgical repair, this number is even greater, nearly 33\%. PAH-CHD has a better prognosis than $\mathrm{PAH}$ caused by other aetiologies; 3-year survival rate for PAH-CHD has been reported to be $77 \%$ compared with only $37 \%$ for PAH due to connective tissue disease and $35 \%$ for untreated IPAH. ${ }^{46}$ Despite the better survival rates in patients with $\mathrm{PAH}-\mathrm{CHD}$, it is important to find effective medication options to manage this condition in order to improve exercise capacity and quality of life while also slowing the rate of clinical deterioration and the need for more definitive treatment (heart and lung transplantation). Current treatment algorithms for PAH-CHD are largely the same as those used for PAH, though the small number of available studies conducted specifically on patients with PAH-CHD calls for the need of a more thorough evaluation of treatment strategies for this population. While many studies that have been performed on patients with $\mathrm{PAH}$ due to a variety of aetiologies have suggested that response to treatment has been similar between patients with IPAH and PAH-CHD, other studies have suggested that this may not be the case for all medications. ${ }^{35} 39$ Furthermore, it is important to consider that PAH-CHD encompasses a variety of pathophysiological processes, and the prognosis and treatment response may vary based on the specific underlying process (eg, PAH-CHD due to ES may not carry the same prognosis nor the same response to treatment as PAH-CHD following corrective cardiac surgery or PAH-CHD in patients with Down syndrome).

In most studies, 6MWD is used as the primary endpoint in assessing the efficacy of each drug in the medical management of PAH-CHD. While not necessarily an indicator of mortality benefit, 6MWD has been validated as a convenient and inexpensive marker for patients' exercise capacity and overall functional status, which corresponds to patients' overall quality of life. 6MWD $>400 \mathrm{~m}$ is considered acceptable in patients with PAH-CHD, while $6 \mathrm{MWD}<332 \mathrm{~m}$ indicates a poor prognosis. ${ }^{4}$ The minimum improvement in 6MWD considered to be clinically important is at least 33-42 $\mathrm{m}$ for patients with PAH. ${ }^{1}$ Patients who received riociguat in PATENT-2 had an increase in 6MWD of $108 \mathrm{~m}$ (29.27\% improvement). Patients receiving bosentan in the open-label extension of BREATHE-5 saw an increase in 6MWD of $60 \mathrm{~m}(17.75 \%$ improvement), with a number of other studies on bosentan showing similar results, at least during the first several months of treatment. Macitentan has shown mixed results in regards to 6MWD, ranging from no improvement to an improvement of $113 \mathrm{~m}$ (58.85\% improvement in ERA-naive patients). These variable findings may be because many of the patients in the macitentan studies were treated with bosentan just prior to their enrolment, which could have blunted macitentan's treatment effect; the large number of patients with Down syndrome included in the macitentan studies may have also contributed to the mixed results as the 6 min walking test is not as well validated for this group of patients. While epoprostenol has been well studied for the management of PAH and is the only drug shown to have a mortality benefit, studies evaluating its use specifically for patients with PAH-CHD are few in number, though the currently available studies report positive results ${ }^{32}$; ; the largest study by Rosenzweig et a $\vec{l}^{3}$ showed an improvement of $52 \mathrm{~m}$ (12.75\% improvement). Regarding the use of sildenafil, Zeng et $a l^{41}$ found that the drug improved 6MWD between 40 and $60 \mathrm{~m}$ (10\%-15\% improvement), though Chau et $a l^{39}$ did not observe a significant improvement in their study. And for tadalafil, Mukhopadhyay et $a l^{43}$ showed an improvement of $43 \mathrm{~m}$ (12.5\% improvement). Given the recommendation that an improvement of 33-42m is clinically important, riociguat, bosentan, macitentan, epoprostenol and sildenafil all met this criterion, in at least one study; however, directly comparing the efficacy of each agent against the others is very difficult due to the fact that each study was conducted over a different length of time, with patients suffering from PAH-CHD due to various aetiologies and of varying degrees of severity, and with each study enrolling patients who were $\mathrm{PAH}$-specific therapy naive, already receiving background therapy with other PAH medications, or a mixture of both.

One concern that has been brought up for bosentan is that some studies have suggested that initial improvements in 6MWD may return to baseline values after long-term use. ${ }^{22-24}$ Van Loon $e t a l^{23}$ suggested that this phenomenon may be more likely to occur in patients with more advanced PAH-CHD, and Duffels et $a l^{24}$ suggested that this may have resulted from either gradual tolerance to bosentan or natural disease progression in their patients. This phenomenon was not observed for the other medications, though this may be related to the fact that there have been more studies conducted on the long-term use of bosentan than on the long-term use of the other agents. It is possible that with further investigation similar observations may be seen for the other drugs as well.

Improvement in WHO FC in response to $\mathrm{PAH}$-specific medications has been shown to be another important finding in patients with PAH. Barst $e t a l^{47}$ looked at 3-year survival in patients with $\mathrm{PAH}$ and found that 3-year survival was better in patients whose WHO FC improved at least one class in response to treatment. Three-year survival was $84 \%$ for those patients whose WHO FC improved, while it was $64 \%$ for those patients whose WHO FC remained the same, and it dropped to only $29 \%$ for those patients whose WHO FC worsened after starting treatment. Among the studies that reported changes in WHO FC, there was usually a significant percentage of patients who improved by at least one class. Perhaps more importantly, for those patients who did not improve, the vast majority at least remained stable at the same class, with very few studies reporting patients who deteriorated to a worse class. 
RV failure is the leading cause of death in patients with PAH. Increased PVR and progressive pulmonary arterial stiffening are the two major factors contributing to increased RV demand. ${ }^{48}$ mPAP has been used to diagnose PAH and to predict survival. Improvements in PVR and mPAP have been used to demonstrate medications' efficacy in reversing pulmonary vasculature remodelling, which may suggest that medications which improve these parameters could play a role in preventing RV failure and improving mortality. After 12 weeks of riociguat in PATENT-1, PVR decreased between $12.03 \%$ and $22.02 \%$, and mPAP decreased by $4.48 \%$ and $6.78 \%$. Similar improvements were seen in the 16-week-long BREATHE-5 trial (placebo-corrected reduction in PVR of $13.78 \%$ and a $7.07 \%$ reduction in mPAP). Other studies on bosentan have shown reductions in PVR between $22.66 \%$ and $36.36 \%{ }^{13} 14{ }^{16}$; some studies also showed a decrease in mPAP between $9.60 \%$ and $13.33 \%$ on bosentan, ${ }^{1421}$ while others failed to show any significant improvement. ${ }^{1617}$ The greatest improvements in PVR and mPAP were seen in the two studies on epoprostenol, which showed reductions in PVR of $48.78 \%$ and $52.00 \%,{ }^{3233}$ and reductions in mPAP of $20.78 \% .^{33}$ The impressive improvements in PVR and mPAP seen with epoprostenol, combined with these parameters' role in preventing RV failure, hint towards a possible mechanism by which epoprostenol improves mortality in PAH-CHD. Interestingly, the studies on sildenafil have also shown impressive improvements in PVR and mPAP, approaching those seen with epoprostenol. Chau et $a l^{39}$ saw a $43.08 \%$ reduction PVR and a $25.71 \%$ decrease in mPAP. Zeng et $a t^{41}$ saw reductions in PVR between $24.76 \%$ and $31.72 \%$; mPAP decreased by $11.28 \%$, but only in the group of patients with PAH-CHD associated with a VSD. Though each of these two sildenafil studies had small sample sizes, the marked improvement in PVR and mPAP draw reason to re-evaluate this drug's potential role in improving mortality in patients with PAH-CHD.

NT-proBNP levels are helpful when assessing a medication's efficacy in the treatment of PAH-CHD because, like PVR and mPAP, the NT-proBNP level has been shown to reflect the severity of RV failure, the leading cause of death in PAH-CHD. NT-proBNP below a median of $553 \mathrm{pg} / \mathrm{mL}$ was related to better 6 -month and 1-year survival rates. ${ }^{4}$ Unfortunately, only a few studies comment on changes in NT-proBNP levels. In PATENT-1, NT-proBNP levels dropped from a mean of 761 to 597 $\mathrm{pg} / \mathrm{mL}$ (21.55\% improvement) after 12 weeks of riociguat $2.5 \mathrm{mg}$. Interestingly, in the group that received the lower dose of riociguat $1.5 \mathrm{mg}$, there was an even greater drop in NT-proBNP levels from a mean of 1352 to $480 \mathrm{pg} / \mathrm{mL}$ (64.50\% improvement). The study by Duffels $e t a l^{24}$ saw no improvement in NT-proBNP in response to bosentan. Blok $e t a l^{31}$ saw a decrease in NT-proBNP from a mean of 723 to $488 \mathrm{pg} / \mathrm{mL}$ ( $48.16 \%$ improvement), and D'Alto $e t$ $a t^{40}$ saw a decrease from 760 to $303 \mathrm{pg} / \mathrm{mL}$ (60.14\% reduction). Based on the overall paucity of data on NT-proBNP in patients with PAH-CHD, it is difficult to draw any hard conclusions on this parameter's role in the prognostication and management of PAH-CHD. Future studies may elect to measure serum levels of this protein to gain more insight into each medication's role in protecting against RV failure.

One concern that has been raised regarding the use of PAH-specific medications in patients with congenital heart defects is that the systemic vasodilation caused by these agents may occur to a greater extent than the intended pulmonary vasodilation, which could result in pulmonary-to-systemic shunting across the structural heart defect and lead to arterial oxygen desaturation. However, arterial oxygen saturation was monitored in most of the studies included in this review, and there were no cases of arterial oxygen desaturation reported. In fact, arterial oxygen saturation increased slightly following treatment in many studies, a finding which was attributed to the improved pulmonary blood flow secondary to pulmonary vasodilation. Based on these findings, it seems unlikely that pulmonary-to-systemic shunting should be a concern when considering whether or not to initiate treatment with PAH-specific medications in patients with PAH-CHD.

\section{LIMITATIONS OF THIS REVIEW}

Most of the limitations of this review are related to the limitations common among the included studies. Small population size was common among many of the studies, especially those studies which included patients with a variety of causes of PAH; when the PAH-CHD subgroup was looked at in those studies, the sample size was usually very small, often $<20$ patients. Also, many of the studies included in this review were of varying durations, which makes making direct comparisons between the results of each study difficult. Additionally, studies which lasted for longer durations may have suffered from bias due to loss to follow-up.

A couple of studies have reported that the effects of medications on PAH may be related to the severity of disease, ${ }^{23}{ }^{24}$ suggesting that the studies which included more patients with advanced disease (eg, patients who were WHO FC III and IV) were more likely to show greater improvement in 6MWD than studies that included more patients with less advanced disease (eg, patients who were WHO FC I and II). Also, many of the studies focused on patients with PAH-CHD due to a specific cause; PATENT-1 and PATENT-2 looked exclusively at patients with PAH-CHD post-corrective cardiac surgery, and many of the other studies assessed patients with PAH-CHD due to ES. Some studies have shown that patients with ES are more responsive to treatment than patients without ES; Duffels $e t a l^{24}$ showed that patients with ES were more likely to exhibit long-term improvement in 6MWD while on bosentan, while patients without ES exhibited a gradual return to baseline by 2 years of treatment. Studies on patients with Down syndrome ${ }^{24-273031}$ have shown variable responses to treatment, most likely due 
to the questionable validity of the $6 \mathrm{~min}$ walking test in this population. Zeng et $a t^{11}$ addressed the issue that the type and location of the congenital heart defect (eg, ASD, VSD, PDA) may also play a role in patients' response to $\mathrm{PAH}$-specific medical therapies, and they found that the location of the defect did not significantly influence patients' response to treatment. More research is necessary to provide additional insight into how the severity and aetiology of patients' congenital heart disease affects their response to treatment.

Another major limitation is that some of the studies in this review evaluated medications used as monotherapy for PAH-CHD, while others evaluated the study drug after patients had received prior treatment with other PAH-specific medications. If patients had already received prior treatment, then their response to the study drug may be blunted by any improvements previously attained in response to those earlier treatments, ${ }^{30} 3149$ a finding which may hold particularly true for the currently available studies on macitentan, where many patients had previously been treated with bosentan for an extended period. Additionally, pharmacokinetic interactions between drugs may also occur; some studies have suggested that bosentan may significantly decrease plasma concentrations of sildenafil when co-administered to patients with $\mathrm{PAH},{ }^{49}{ }^{50}$ and it is possible that similar interactions may occur between other PAH medications as well.

Finally, PATENT-1, PATENT-2, BREATHE-5 and ALPHABET were placebo-controlled trials. However, many of the studies were not placebo-controlled, making it difficult to assess whether or not a placebo effect was impacting the results reported in those studies.

\section{FUTURE STUDIES}

More randomised, double-blinded placebo-controlled trials that assess the use of each medication specifically in large numbers of patients with PAH-CHD would help provide the highest quality of data to help draw comparisons between the efficacy of each medication and assist in the creation of treatment algorithms tailored specifically for patients with PAH-CHD. Of course, implementation of such studies would prove difficult as the overall prevalence of PAH-CHD is quite low and can make enrolling sufficient numbers of patients to allow for meaningful randomised, double-blinded placebo-controlled trials very difficult. There may also be much to learn if more studies were designed to assess each medication's efficacy when the patient population consists exclusively of patients with the same underlying cardiac defect, so as to remove confounding that might be introduced by the variable pathophysiology, illness severity and potential treatment response from each type of cardiac defect. Though this too would likely be difficult to arrange due to the already small pool of patients with PAH-CHD, where further subdivision into groups consisting of only a single specific cardiac defect may drastically hinder the ability to create studies with sufficient power to draw any meaningful conclusions.

Future studies may choose to evaluate each medication as monotherapy for treatment-naive patients, so as to avoid any confounding that may occur from interactions between PAH-specific medications, though again, the number of patients with PAH-CHD is already quite small and further narrowing of the patient pool to treatment-naive patients would make for a challenging and limited enrolment process. Furthermore, this could introduce selection bias that would favour healthier patients who are for the first time requiring treatment with advanced therapies and select against sicker patients who require multiple medications.

In regards to endpoints, the 6 min walking test is often used as the gold-standard test for assessing PAH medications' efficacy, though there have been few studies which have evaluated these medications' effects on other important outcomes, most notably mortality. Currently, epoprostenol is the only medication shown to improve mortality in patients with PAH-CHD, and future studies may choose to assess whether other medications can also lead to a mortality benefit in these patients.

Finally, several PAH-specific medications, such as ambrisentan, macitentan, treprostinil, iloprost, selexipag and vardenafil, have yet to be studied for the management of PAH-CHD, and future studies may look to see what roles these agents could play in the management of this disease.

\section{SUMMARY}

PAH-CHD is becoming an increasingly common form of PAH, one which could benefit from a more thorough evaluation of appropriate treatment strategies. While the current approach of using the same treatment algorithms for PAH-CHD as those used for other forms of PAH has shown to be effective, subtle differences in the pathophysiology and haemodynamics of PAH-CHD mean that the assumption that medications which work for other forms of PAH are equally appropriate for PAH-CHD may not necessarily hold true. This review found that riociguat, bosentan, epoprostenol and sildenafil were all capable of improving functional capacity and haemodynamic parameters in patients with PAH-CHD; however, whether this corresponds to improved mortality remains to be seen, with only epoprostenol having been shown to have a survival benefit at this time. Furthermore, this review did not find that any of the PAH-specific medications resulted in worsening of pulmonary-to-systemic shunting (as determined by arterial oxygen desaturation) in any study, which was one of the biggest concerns regarding the use of these agents in patients with structural heart defects. Therefore, this concern should not discourage physicians from prescribing these agents to patients with PAH-CHD. Making direct comparisons between the efficacy of each medication remains difficult as many of the studies currently 
available are of varying durations, have small sample sizes and enrol patients whom may or may not be receiving background therapy with other PAH-specific medications. Future investigations consisting of randomised, placebo-controlled trials which enrol large numbers of patients not receiving additional background therapy may provide new insights into each medication's role in the management of PAH-CHD.

\section{Competing interests None declared.}

Provenance and peer review Not commissioned; internally peer reviewed.

Data sharing statement Individual participant data will not be available. Study protocol (ie, trial inclusion/exclusion criteria) will be available, and this will be available at the time of publication within the primary text.

Open Access This is an Open Access article distributed in accordance with the Creative Commons Attribution Non Commercial (CC BY-NC 4.0) license, which permits others to distribute, remix, adapt, build upon this work non-commercially, and license their derivative works on different terms, provided the original work is properly cited and the use is non-commercial. See: http://creativecommons.org/ licenses/by-nc/4.0/

(c) Article author(s) (or their employer(s) unless otherwise stated in the text of the article) 2018. All rights reserved. No commercial use is permitted unless otherwise expressly granted.

\section{REFERENCES}

1. Rosenkranz S, Ghofrani HA, Beghetti M, et al. Riociguat for pulmonary arterial hypertension associated with congenital heart disease. Heart 2015;101:1792-9.

2. Simonneau G, Gatzoulis MA, Adatia I, et al. Updated clinical classification of pulmonary hypertension. J Am Coll Cardiol 2013;62:D34-41.

3. Galie N, Manes A, Palazzini M, et al. Management of pulmonary arterial hypertension associated with congenital systemicto-pulmonary shunts and Eisenmenger's syndrome. Drugs 2008;68:1049-66.

4. Galiè N, Hoeper MM, Humbert M, et al. Guidelines for the diagnosis and treatment of pulmonary hypertension. Eur Respir $J$ 2009;34:1219-63.

5. Tonelli AR, Alnuaimat $\mathrm{H}$, Mubarak $\mathrm{K}$, et al. Pulmonary vasodilator testing and use of calcium channel blockers in pulmonary arterial hypertension. Respir Med 2010;104:481-96.

6. Chin KM, Rubin LJ. Pulmonary arterial hypertension. J Am Coll Cardiol 2008;51:1527-38.

7. Gatzoulis MA, Alonso-Gonzalez R, Beghetti M. Pulmonary arterial hypertension in paediatric and adult patients with congenital heart disease. Eur Respir Rev 2009;18:154-61.

8. Barst RJ, McGoon M, Torbicki A, et al. Diagnosis and differential assessment of pulmonary arterial hypertension. J Am Coll Cardiol 2004;43:S40-7.

9. Pharma Bayer AG. Adempas $®$ US prescribing information, 2013. http://labeling.bayerhealthcare.com/html/products/pi/Adempas_PI. pdf.

10. Stasch JP, Evgenov OV. Soluble guanylate cyclase stimulators in pulmonary hypertension. Handb Exp Pharmacol 2013;218:279-313.

11. Ibrahim R, Granton JT, Mehta S. An open-label, multicentre pilot study of bosentan in pulmonary arterial hypertension related to congenital heart disease. Can Respir J 2006;13:415-20.

12. Gatzoulis MA, Rogers P, Li W, et al. Safety and tolerability of bosentan in adults with Eisenmenger physiology. Int $J$ Cardiol 2005;98:147-51.

13. D'Alto M, Vizza CD, Romeo E, et al. Long term effects of bosentan treatment in adult patients with pulmonary arterial hypertension related to congenital heart disease (Eisenmenger physiology): safety, tolerability, clinical, and haemodynamic effect. Heart 2007;93:621-5.

14. Benza RL, Rayburn BK, Tallaj JA, et al. Efficacy of bosentan in a small cohort of adult patients with pulmonary arterial hypertension related to congenital heart disease. Chest 2006;129:1009-15.

15. Kotlyar E, Sy R, Keogh AM, et al. Bosentan for the treatment of pulmonary arterial hypertension associated with congenital cardiac disease. Cardiol Young 2006;16:268-74.

16. Sitbon O, Beghetti M, Petit J, et al. Bosentan for the treatment of pulmonary arterial hypertension associated with congenital heart defects. Eur J Clin Invest 2006;36(Suppl 3):25-31.
17. Schulze-Neick I, Gillbert N, Ewert R, et al. Adult patients with congenital heart disease and pulmonary arterial hypertension: first open prospective multicenter study of bosentan therapy. Am Heart $J$ 2005; 150:716.e7-e12.

18. Diller GP, Dimopoulos K, Kaya MG, et al. Long-term safety, tolerability and efficacy of bosentan in adults with pulmonary arterial hypertension associated with congenital heart disease. Heart 2007;93:974-6.

19. Galiè N, Beghetti M, Gatzoulis MA, et al. Bosentan therapy in patients with Eisenmenger syndrome: a multicenter, double-blind, randomized, placebo-controlled study. Circulation 2006;114:48-54.

20. Gatzoulis MA, Beghetti M, Galiè N, et al. Longer-term bosentan therapy improves functional capacity in Eisenmenger syndrome: results of the BREATHE- 5 open-label extension study. Int $J$ Cardiol 2008;127:27-32

21. Apostolopoulou SC, Manginas A, Cokkinos DV, et al. Effect of the oral endothelin antagonist bosentan on the clinical, exercise, and haemodynamic status of patients with pulmonary arterial hypertension related to congenital heart disease. Heart 2005;91:1447-52.

22. Apostolopoulou SC, Manginas A, Cokkinos DV, et al. Long-term oral bosentan treatment in patients with pulmonary arterial hypertension related to congenital heart disease: a 2-year study. Heart 2007;93:350-4.

23. van Loon RL, Hoendermis ES, Duffels MG, et al. Long-term effect of bosentan in adults versus children with pulmonary arterial hypertension associated with systemic-to-pulmonary shunt: does the beneficial effect persist? Am Heart J 2007;154:776-82.

24. Duffels MG, Vis JC, van Loon RL, et al. Effect of bosentan on exercise capacity and quality of life in adults with pulmonary arterial hypertension associated with congenital heart disease with and without Down's syndrome. Am J Cardiol 2009;103:1309-15.

25. Kermeen FD, Franks C, O'Brien K, et al. Endothelin receptor antagonists are an effective long term treatment option in pulmonary arterial hypertension associated with congenital heart disease with or without trisomy 21. Heart, Lung and Circulation 2010;19:595-600.

26. D'Alto M, Romeo E, Argiento P, et al. Therapy for pulmonary arterial hypertension due to congenital heart disease and Down's syndrome. Int J Cardiol 2013;164:323-6.

27. Barst RJ, Langleben D, Frost $A$, et al. Sitaxsentan therapy for pulmonary arterial hypertension. Am J Respir Crit Care Med 2004;169:441-7.

28. Barst RJ. A review of pulmonary arterial hypertension: role of ambrisentan. Vasc Health Risk Manag 2007;3:11-22.

29. Galie N, Olschewski H, Oudiz RJ, et al. Ambrisentan for the treatment of pulmonary arterial hypertension. Circulation 2008;117:3010-9.

30. Herbert S, Gin-Sing W, Howard L, et al. Early experience of macitentan for pulmonary arterial hypertension in adult congenital heart disease. Heart Lung Circ. In Press. 2017;26:1113-6.

31. Blok IM, van Riel A, van Dijk APJ, et al. From bosentan to macitentan for pulmonary arterial hypertension and adult congenital heart disease: further improvement? Int J Cardiol 2017;227:51-2.

32. Fernandes SM, Newburger JW, Lang P, et al. Usefulness of epoprostenol therapy in the severely ill adolescent/adult with Eisenmenger physiology. Am J Cardiol 2003:91:632-5.

33. Rosenzweig EB, Kerstein D, Barst RJ. Long-term prostacyclin for pulmonary hypertension with associated congenital heart defects. Circulation 1999;99:1858-65.

34. Skoro-Sajer N, Lang I, Naeije R. Treprostinil for pulmonary hypertension. Vasc Health Risk Manag 2008;4:507-13.

35. Melian EB, Goa KL. Beraprost: a review of its pharmacology and therapeutic efficacy in the treatment of peripheral arterial disease and pulmonary arterial hypertension. Drugs 2002;62:107-33.

36. Galiè N, Humbert M, Vachiéry J-L, et al. Effects of beraprost sodium, an oral prostacyclin analogue, in patients with pulmonary arterial hypertension: a randomized, double-blind, placebo-controlled trial. J Am Coll Cardiol 2002;39:1496-502.

37. Olschewski H, Simonneau G, Galiè N, et al. Inhaled lloprost for Severe Pulmonary Hypertension. N Engl J Med Overseas Ed 2002;347:322-9.

38. Sitbon O, Channick R, Chin KM, et al. Selexipag for the treatment of pulmonary arterial hypertension. N Engl J Med Overseas Ed 2015;373:2522-33.

39. Chau EMC, Fan KYY, Chow WH. Effects of chronic sildenafil in patients with Eisenmenger syndrome versus idiopathic pulmonary arterial hypertension. Int J Cardiol 2007;120:301-5.

40. D'Alto M, Romeo E, Argiento P, et al. Bosentan-sildenafil association in patients with congenital heart disease-related pulmonary arterial hypertension and Eisenmenger physiology. Int J Cardiol 2012;155:378-82. 
41. Zeng WJ, Lu XL, Xiong CM, et al. The efficacy and safety of sildenafil in patients with pulmonary arterial hypertension associated with the different types of congenital heart disease. Clin Cardiol 2011;34:513-8.

42. Bischoff E. Potency, selectivity, and consequences of nonselectivity of PDE inhibition. Int J Impot Res 2004;16:S11-14.

43. Mukhopadhyay S, Sharma M, Ramakrishnan S, et al. Phosphodiesterase- 5 inhibitor in Eisenmenger syndrome: a preliminary observational study. Circulation 2006;114:1807-10.

44. Galie N, Corris PA, Frost A, et al. Updated treatment algorithm of pulmonary arterial hypertension. J Am Coll Cardiol 2013;62:25.

45. Jing ZC, Yu ZX, Shen JY, et al. Vardenafil in pulmonary arterial hypertension: a randomized, double-blind, placebo-controlled study. Am J Respir Crit Care Med 2011;183:1723-9.

46. Mulder BJM. Changing demographics of pulmonary arterial hypertension in congenital heart disease. European Respiratory Review 2010;19:308-13.
47. Barst RJ, Chung L, Zamanian RT, et al. Functional class improvement and 3-year survival outcomes in patients with pulmonary arterial hypertension in the REVEAL Registry. Chest 2013;144:160-8.

48. Wang Z, Chesler NC. Pulmonary vascular wall stiffness: an important contributor to the increased right ventricular afterload with pulmonary hypertension. Pulm Circ 2011;1:212-23.

49. Galiè N, Brundage BH, Ghofrani HA, et al. Tadalafil therapy for pulmonary arterial hypertension. Circulation 2009;119:2894-903.

50. Paul GA, Gibbs JSR, Boobis AR, et al. Bosentan decreases the plasma concentration of sildenafil when coprescribed in pulmonary hypertension. Br J Clin Pharmacol 2005;60:107-12.

51. Engelfriet PM, Duffels MGJ, Moller T, et al. Pulmonary arterial hypertension in adults born with a heart septal defect: the Euro Heart Survey on adult congenital heart disease. Heart 2007;93:682-7. 